\title{
Comparação entre tecnologias de climatização para criação de frangos quanto a energia, ambiência e produtividade
}

\author{
Leda Bueno' \& Luiz A. Rossi ${ }^{1}$
}

\begin{abstract}
RESUMO
Com o objetivo de comparar duas opções tecnológicas de climatização na produção de frangos de corte, foi realizado, na cidade de Rio Claro, SP, um experimento em dois galpões comerciais de uma granja, um com sistema de ventilação e nebulização e com 13 aves $\mathrm{m}^{-2}$ (G1) e o outro com sistema de ventilação tipo túnel, composto de exaustores e bomba de nebulização e com 18 aves $\mathrm{m}^{-2}$ (G2). A duração do experimento foi de 14 meses com análise completa de cinco lotes de criação em diferentes estações do ano, onde foram analisadas as variáveis relativas à eficiência energética, ao conforto térmico e índices produtivos. Observou-se que os dois galpões apresentaram valores semelhantes para o conforto térmico e para os índices de produtividade animal. Em relação ao consumo de energia elétrica, G2 apresentou valores maiores que G1, porém com uma produção de frangos 38\% maior que G1. Os índices de eficiência energética foram baixos, demonstrando haver oportunidade para adoção de medidas de conservação e de racionalização de energia elétrica.
\end{abstract}

Palavras-chave: avicultura, energia elétrica, conforto térmico

\section{Comparison between technologies of climatization for creation of broiler considering the energy, environment and productivity}

\begin{abstract}
With the objective to compare two technological options of climatization for the production of broilers, in the city of Rio Claro-São Paulo state, an experiment was carried out in two commercial sheds of a farm, being one with system of ventilation and nebulization and 13 birds $\mathrm{m}^{-2}(\mathrm{G} 1)$ and the other with system of ventilation composed of tunnel of exhaust fans and pump of nebulization and with 18 birds $\mathrm{m}^{-2}(\mathrm{G} 2)$. The period of the experiment was 14 months with complete analysis of five lots of creation in different seasons of the year, where the variable related to energy efficiency, thermal comfort and productive indices were analyzed. It was observed that the two sheds presented similar values of thermal comfort and animal productivity. In relation to the consumption of electrical energy, G2 presented higher values than G1, however with chicken production 38\% more than G1. The indices of energy efficiency had been low, demonstrating the possibilities for adoption of measures for conservation and rationalization of electrical energy.
\end{abstract}

Keywords: aviculture, electrical energy, thermal comfort 


\section{INTRODUÇÃO}

O consumo de carne de frangos cresceu 88\% de 1961 até o ano de 2002. Nas últimas quatro décadas, o Brasil conquistou espaço significativo na produção avícola mundial, visto que, de 1,4\% evolui a um patamar de 10,5\% (APA, 2005), em 2004, foi considerado o segundo maior produtor de carne de frangos, apresentando um volume total de 8,4 milhões de toneladas e o maior exportador mundial, com 2,4 milhões de toneladas de carne de frango (ABEF, 2005). No início dos anos 80, um frango com 70 dias de idade atingia aproximadamente $2,0 \mathrm{~kg}$ de peso vivo, com conversão alimentar média de 3,5, atualmente, em apenas 42 dias é possível se obter frangos com $2,3 \mathrm{~kg}$ de peso vivo e conversão alimentar de 1,8. A alta produção de carne por área em curto espaço de tempo, se deve aos avanços científicos conquistados na genética, nutrição, sanidade e manejo, fazendo com que a produção de frangos de corte atingisse um patamar elevado quanto à produção animal. Observa-se que, apesar de ter conquistado altos índices em produção, as instalações avícolas são um dos pontos concentradores de preocupações, em se tratando do conforto térmico para frangos de corte (Abreu \& Abreu, 2001).

Os aviários implantados no Brasil apresentam forte influência da indústria de equipamentos existentes nos países de clima temperado (USA e países da Europa); este fato, associado a pouca observância nas fases de planejamento e concepção arquitetônica, sem os ajustes necessários ao bioclima local, produz instalações que geram desconforto térmico, aumento de doenças ligadas à perda da qualidade do ar e da dependência energética. Ante esta constatação, encontramse altas taxas de mortalidade no período final de criação, diminuição dos índices de produtividade no segmento de corte e aumento dos gastos com energia elétrica nos períodos quentes do ano (Abreu \& Abreu, 2001).

A ave adulta é um animal que se adapta melhor a ambientes frios, pois seu sistema termorregulador é mais adequado para reter calor que para dissipá-lo. Quando exposta ao estresse térmico, por elevadas temperaturas, a ave apresenta diminuição no consumo de ração e, em conseqüência, redução no ganho de peso e pior conversão alimentar (Müller, 1982; Nääs, 1989).

O sucesso ou fracasso de uma criação de frangos de corte está diretamente relacionado às condições ambientais a que estes estão submetidos. Os altos valores de temperatura ambiente provocam queda de produção e mortalidade no meio avícola (Campos, 1995). Tal fato se vem agravando à medida que a densidade de criação é aumentada e, também, pelo fato de que a ave vem sendo desenvolvida geneticamente, tornando-se mais precoce e produtiva (Macari, 1998).

Uma das conseqüências que advêm da climatização do galpão, para se evitar o estresse calórico, é o consumo de energia elétrica, uma vez que os equipamentos de climatização, tais como ventiladores, exaustores e nebulizadores, passam a funcionar com maior freqüência, aumentando o consumo de energia elétrica. Esta energia, utilizada nos galpões para alimentação, iluminação e, principalmente, manutenção do conforto térmico animal, tem extrema importân- cia na quantificação de custos de produção, relativamente aos equipamentos que são utilizados e à sua relação benefício/ custo, no que diz respeito ao consumo de energia elétrica.

Segundo Nääs et al. (2001) climatizar é adaptar o ambiente interno da construção às condições ideais de alojamento da ave, tendo sempre como parâmetro de referência às condições exteriores. São considerados, portanto, sistemas de climatização, aqueles que utilizam equipamentos de ventilação, exaustão, nebulização e painéis de resfriamento adiabático. Atingir o conforto térmico no interior dessas instalações avícolas, face às condições climáticas inadequadas, torna-se um desafio, uma vez que situações extremas de calor ou frio afetam consideravelmente a produção. A climatização se torna então, uma saída estratégica para se criar uma situação de certa independência do clima externo.

Os mesmos autores descrevem os sistemas utilizados neste trabalho da seguinte maneira:

- Túnel associado à refrigeração adiabática é o sistema definido como forma de climatização que associa o sistema de ventilação em túnel com um sistema de resfriamento, geralmente envolvendo o uso de áreas molhadas ou painel evaporativo. O princípio é que, ao atravessar a área molhada, o ar se resfria e é movimentado ao longo da instalação, no sentido da exaustão.

- Ventilação com nebulização, é a união de ventilação e nebulização associadas a um manejo sincronizado do sistema. O uso desses dois sistemas mostra-se insuficiente para controlar os altos níveis de estresse nas aves quando o clima se encontra em temperatura e umidade relativas elevadas.

No caso de frangos de corte adultos, a temperatura ambiente deve ser de $21,1^{\circ} \mathrm{C}$, a umidade relativa $50 \%$, a renovação de ar deve ocorrer em menos de 1,3 min. e a velocidade máxima do ar deve estar entre 2,29 e 2,41 $\mathrm{m} \mathrm{s}^{-1}$ (Barnwell \& Rossi, 2003).

Através do exposto este trabalho tem o objetivo de comparar duas técnicas de climatização na produção de frangos de corte com densidades animais diferentes quanto a produção animal e o uso racional de energia elétrica.

\section{MATERIAL E MÉTODOS}

Para melhor caracterização do consumo de energia elétrica e produtividade do animal, nas várias estações do ano, a aquisição e análise dos dados foram feitas para cinco lotes de criação em uma granja comercial de frangos de corte localizada na região de Rio Claro, SP entre de 2002 e 2003. A Tabela 1 apresenta o período e a duração dos lotes analisados.

Os galpões foram denominados galpão G1 (sistema convencional) e galpão G2 (sistema alta densidade) e possuíam padronização básica, tanto em relação às medidas quanto ao tipo de material usado na construção. No caso em análise, as dimensões eram: $115 \mathrm{~m}$ de comprimento, $12 \mathrm{~m}$ de largura, 3,5 m de alturas laterais de cumeeira, 4,5 m de altura da cumeeira, paredes laterais de $50 \mathrm{~cm}$ de altura, 
Tabela 1. Período de duração dos lotes analisados

\begin{tabular}{ccccc}
\hline Lotes & Galpão & Período do lote & Dias & Estação do ano \\
\hline 1 & G1 & 30/09/2002 a 17/11/2002 & 48 & Primavera-Verão \\
1 & G2 & 30/09/2002 a 17/11/2002 & 48 & Primavera-Verão \\
2 & G1 & $10 / 02 / 2003$ a 01/04/2003 & 50 & Verão-Outono \\
\hline 2 & G2 & $10 / 02 / 2003$ a 01/04/2003 & 50 & Verão-Outono \\
\hline 3 & G1 & $17 / 04 / 2003$ a 10/06/2003 & 54 & Outono-Inverno \\
\hline 3 & G2 & $17 / 04 / 2003$ a 12/06/2003 & 56 & Outono-Inverno \\
\hline 4 & G1 & $26 / 06 / 2003$ a 31/07/2003 & 35 & Inverno \\
\hline 4 & G2 & $26 / 06 / 2003$ a 10/08/2003 & 45 & Inverno \\
\hline 5 & G1 & $28 / 08 / 2003$ a 09/10/2003 & 42 & Primavera-Verão \\
\hline 5 & G2 & $28 / 08 / 2003$ a 09/10/2003 & 42 & Primavera-Verão \\
\hline
\end{tabular}

telhas do tipo calhetão de fibrocimento, lanternim ondulado, piso de concreto, tela metálica de inox para separação dos box no interior dos galpões e cortinas laterais.

A Figura 1 (A) e (B) mostra o esquema de distribuição dos ventiladores e das linhas de nebulização no interior do galpão G1 e o posicionamento dos exaustores e das linhas de nebulização no galpão G2, respectivamente.

A Tabela 2 descreve as principais características de cada um dos galpões.

A Tabela 3 mostra a rotina de acionamento dos equipamentos, tanto do galpão G1 como do galpão G2.

A aquisição de dados foi feita por dois sistemas distintos, em que o Field logger fazia a aquisição de dados de temperatura e umidade relativa do ar e o HX 600, que adquiria dados de grandezas elétricas.

Para cada lote de produção, obtiveram-se as variáveis produtivas mortalidade, conversão alimentar e ganho de
Tabela 2. Caracterização dos galpões G1 e G2

\begin{tabular}{|c|c|c|}
\hline & Galpão G1 & Galpão G2 \\
\hline $\begin{array}{l}\text { Densidade animal e } \\
\text { linhagem }\end{array}$ & 13 aves $m^{-2}-$ Ross & 18 aves $m^{-2}-$ Ross \\
\hline Sistema de climatização & $\begin{array}{l}\text { Ventilação com nebuli- } \\
\text { zação (8 ventiladores) }\end{array}$ & $\begin{array}{l}\text { Túnel associado a refri- } \\
\text { geração adiabática (8 } \\
\text { exaustores) }\end{array}$ \\
\hline Acionamento & Parcialmente manual & Automático \\
\hline $\begin{array}{l}\text { Linhas de comedouros/ } \\
\text { silo de abastecimento }\end{array}$ & $2-1$ & $3-1$ \\
\hline № de lâmpadas/potência & 40/40W & 40/40W \\
\hline Nebulização & 2 linhas & 2 linhas \\
\hline
\end{tabular}

Tabela 3. Rotina de acionamento dos equipamentos elétricos dos galpões G1 e G2

\begin{tabular}{lll}
\hline & \multicolumn{1}{c}{ G1 } & \multicolumn{1}{c}{ Galpões } \\
\cline { 2 - 3 } Ventilação & $\begin{array}{l}\text { Acionamento manual ao } \\
\text { atingir } 25^{\circ} \mathrm{C}\end{array}$ & $\begin{array}{l}\text { Acionamento automático pelo } \\
\text { equipamento Climatc dividido } \\
\text { em duas etapas: } 25^{\circ} \mathrm{C} \text { primeira } \\
\text { bateria de exaustores e } 27^{\circ} \mathrm{C} \\
\text { segunda bateria de exaustores }\end{array}$ \\
$\begin{array}{ll}\text { Lomedouro e silo } \\
\text { Bompadas }\end{array}$ & $\begin{array}{l}\text { Período intermitente, esvaziamento do prato } \\
18: 00 \text { às } 06: 00 \mathrm{~h}\end{array}$ \\
\hline $\begin{array}{l}\text { Automático pelo equipamento Climatc/acionamento abaixo } \\
\text { de } 65 \% \text { e desacionamento ao atingir } 80 \% \text { de umidade } \\
\text { relativa do ar }\end{array}$
\end{tabular}

peso diário da linhagem Ross.

A Tabela 4 apresenta os valores padrões de produtividade animal, citados pela Agroceres Ross (2000), para sistema misto de criação.

A.

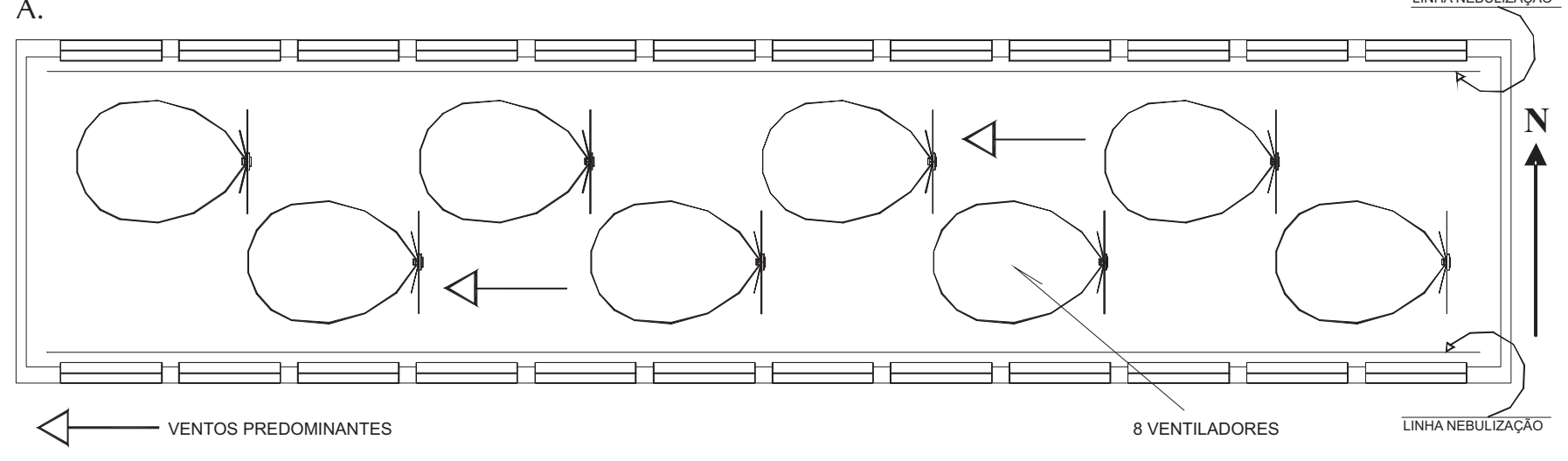

B.

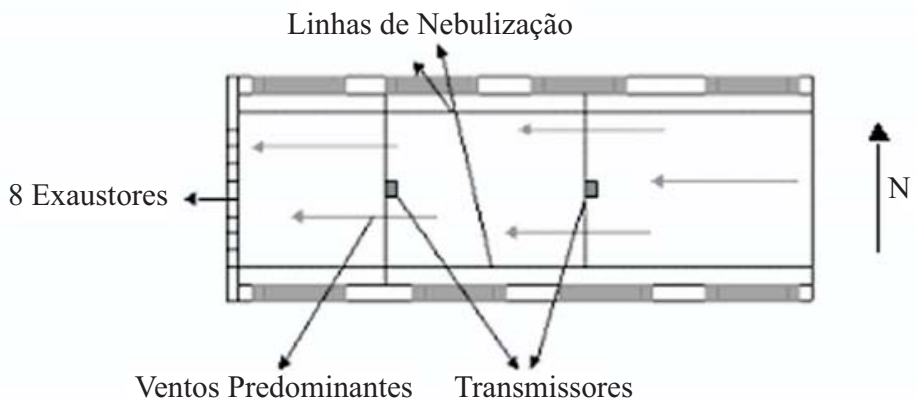

Figura 1. Esquema de distribuição: (A) dos ventiladores e linhas de nebulização do galpão G1, (B) dos exaustores e linhas de nebulização do galpão G2 
Tabela 4. Padrões de produtividade animal de aves da linhagem Ross em lote misto

\begin{tabular}{ccc}
\hline $\begin{array}{c}\text { Mortalidade } \\
(\%)\end{array}$ & $\begin{array}{c}\text { Ganho de Peso Diário } \\
(\mathbf{g})\end{array}$ & $\begin{array}{c}\text { Convesão } \\
\text { Alimentar }\end{array}$ \\
2,64 & 57,90 & 1,72 \\
\hline
\end{tabular}

Relacionaram-se os dados das variáveis ambientais (temperatura do ar e umidade relativa do ar) e das variáveis elétricas (consumo em kWh, demanda de potência em kW e fator de potência), para se obter as principais afinidades com a produtividade animal, em cada sistema de criação.

\section{Análise estatística}

Por se tratar de duas estruturas isoladas $30 \mathrm{~m}$, embora semelhantes do ponto de vista construtivo e com densidades de animais totalmente diferentes, foi realizada análise estatística através da comparação das médias horárias de Consumo de Energia Elétrica (C), Temperatura Média do Ar (TMA) e Umidade Relativa Média do Ar (UR) dos Galpões G1 e G2, separadamente, para cada uma das variáveis citadas anteriormente, através da realização do teste T com nível de significância a 5\%, precedido pelo Teste F para a análise da variância equivalente das médias, quando se analisou a diferença estatisticamente significativa desses dois galpões.

\section{RESULTADOS E DISCUSSÃO}

\section{Variáveis energéticas}

A Figura 2 ilustra o fator de potência médio encontrado nos equipamentos dos galpões G1 e G2 nos lotes analisados.

O fator de potência, tanto do galpão G1 como do G2 manteve-se durante todos os lotes de análise, abaixo de 0,92, que é o valor normatizado pela Agência Nacional de Energia Elétrica. Esta característica se evidenciou pelo fato de existirem muitos motores de pequena potência que, normalmente, possuem fator de potência baixo, demonstrando o uso e aproveitamento inadequados da energia destinada aos equipamentos instalados em cada sistema de produção, tanto é que havia faturamento de excedente reativo na conta de energia do posto de transformação da granja ao qual estavam ligados esses galpões; disto, decorre a necessidade da implan-

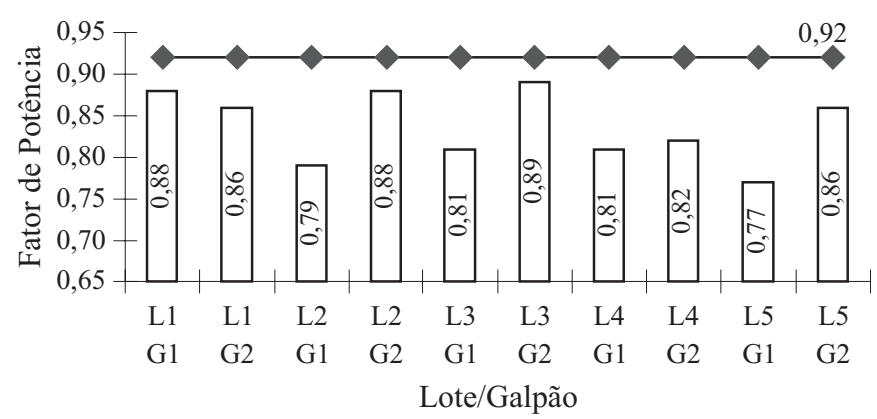

Fator de Potência $\longrightarrow$ Norma ANEEL

Figura 2. Média do fator de potência

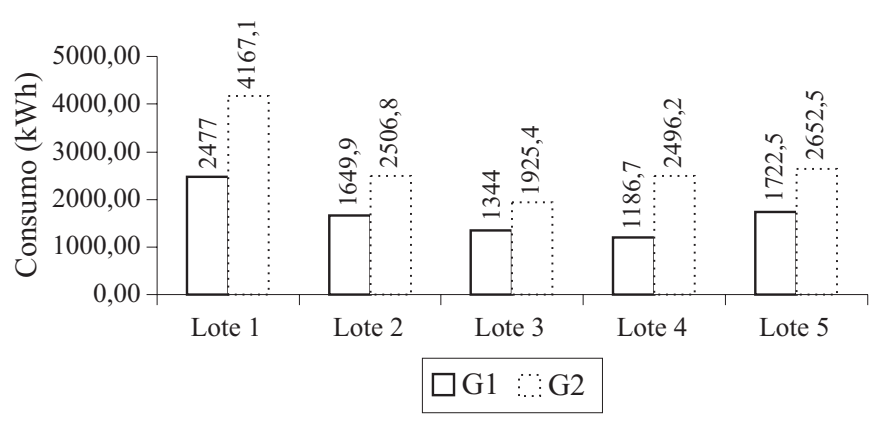

Figura 3. Consumo em kWh de ambos os galpões

tação de medidas de conservação de energia elétrica nos equipamentos utilizados nos dois sistemas de produção.

Na Figura 3 é apresentado o consumo em kWh de ambos os galpões nos cinco lotes analisados.

Observa-se, na Figura 3, que em G2, independentemente da estação do ano e do lote analisado, o consumo de energia elétrica é maior que aquele de G1; nota-se, também, que nos lotes que apresentaram valores de TMA mais baixa (lotes 3, 4 e 5) o consumo de energia elétrica também foi menor. O maior consumo em G2 já era esperado em virtude da potência instalada de equipamentos que proporcionam conforto térmico para aves alojadas neste galpão e o menor consumo em estações do ano mais frias devido, também, à menor utilização dos equipamentos responsáveis por climatizar o ambiente.

Ilustra-se, na Figura 4, a demanda em kW dos dois galpões nos lotes analisados.

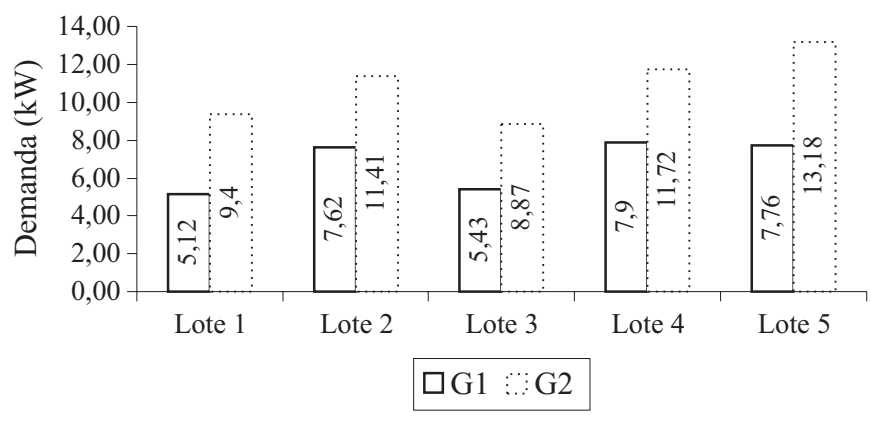

Figura 4. Demanda em kW de ambos os galpões

Do mesmo modo que ocorreu com o consumo de energia elétrica, nota-se que G1 apresenta menor valor de demanda que G2, em todos os lotes analisados, e os valores em estações mais quentes são maiores em relação a estações do ano mais frias, era esperado em razão da menor potência dos equipamentos instalados em G1 e o maior acionamento dos ventiladores e nebulizadores em épocas do ano mais quentes.

\section{Índices de eficiência energética}

A Tabela 5 apresenta os valores dos principais índices de eficiência energética encontrados para G1 e G2, nos cinco lotes experimentais.

Observa-se na Tabela 5, que em todos os lotes analisados G1 apresentou valores (consumo específico por ave e por 
Tabela 5. Principais índices de eficiência energética

\begin{tabular}{ccccc}
\hline Lote & Galpão & $\begin{array}{c}\text { Consumo Específico } \\
\text { (Kwh/ave) }\end{array}$ & $\begin{array}{c}\text { Consumo Específico } \\
\text { (Kwh/kg) }\end{array}$ & Fator de carga \\
\hline 1 & 1 & 0,143 & 0,086 & 0,420 \\
1 & 2 & 0,176 & 0,111 & 0,385 \\
2 & 1 & 0,094 & 0,054 & 0,180 \\
2 & 2 & 0,104 & 0,064 & 0,183 \\
3 & 1 & 0,075 & 0,042 & 0,191 \\
3 & 2 & 0,078 & 0,043 & 0,162 \\
4 & 1 & 0,069 & 0,054 & 0,179 \\
4 & 2 & 0,106 & 0,090 & 0,197 \\
5 & 1 & 0,102 & 0,058 & 0,220 \\
5 & 2 & 0,112 & 0,064 & 0,200 \\
\hline
\end{tabular}

quilo de frango produzido) menores que aqueles de G2, porém esses valores foram muito semelhantes entre si na maioria dos lotes e se deve levar em consideração o maior valor agregado no final de cada lote de produção de G2, já que este possui densidade de 18 aves $\mathrm{m}^{-2}$, sendo seu produto $38 \%$ maior que G1, no mesmo espaço e período de tempo.

Para ambos os galpões e em todos os lotes analisados, o fator de carga foi distante do valor 1, indicando que há necessidade de implantação de medidas de racionalização e conservação do uso de energia elétrica, desde que adotadas algumas soluções de operação de carga, como instalação de bancos capacitores para correção do fator de potência, redimensionamento de vários cabos alimentadores, já que os que lá estão se encontram sobrecarregados, substituição de lâmpadas incandescentes por fluorescentes compactas, estabelecimento e implantação de um programa de manutenção preventiva e treinamento de pessoal para operar adequadamente as cargas elétricas lá existentes.

\section{Relação entre valores de consumo de energia elétrica (kWh) e de grandezas ambientais}

A relação entre os valores de consumo em kWh e os dados ambientais, mostra o comportamento do consumo médio horário (kWh) dos equipamentos responsáveis pelo conforto térmico em cada um dos galpões com as variações das temperaturas e umidades médias diárias. Este procedimento se dirige a todos os lotes de frangos de corte analisados, mas se apresenta como exemplo apenas o lote 1 , já que este caracterizou melhor o consumo de eletricidade.

A Tabela 6 ilustra a variação do consumo dos ventiladores e exaustores em relação à temperatura média do ar nos galpões G1 e G2 e a variação do consumo da bomba de nebulização, em função da umidade relativa do ar no galpão G2, para os dias em que estes equipamentos permaneceram ligados em todo o lote e não para o período de duração do experimento.

Nota-se na Tabela 6 e durante o decorrer do lote, que os ventiladores e exaustores permaneceram acionados para controlar o aumento da TMA no decorrer do lote. Observa-se o mesmo comportamento no acionamento da bomba de nebulização, que ficou acionada durante todo o lote para não deixar a umidade chegar a níveis críticos para os animais; no entanto, é conveniente ressaltar, que não há correlação linear entre os fatores.
Tabela 6. Variação do consumo de equipamentos de climatização com índices de conforto térmico

\begin{tabular}{ccccccc}
\hline & \multicolumn{3}{c}{ Ventilador G1 } & \multicolumn{2}{c}{ Exaustor G2 } & \multicolumn{2}{c}{ Bomba G2 } \\
\cline { 2 - 7 } Data & $\begin{array}{c}\text { Temperatura } \\
\text { ('C) }\end{array}$ & $\begin{array}{c}\text { (kWh) } \\
\text { (kWmo }\end{array}$ & $\begin{array}{c}\text { Temperatura } \\
\text { ('C) }\end{array}$ & $\begin{array}{c}\text { Consumo } \\
\text { (kWh) }\end{array}$ & $\begin{array}{c}\text { Umidade } \\
\text { (\%) }\end{array}$ & $\begin{array}{c}\text { Consumo } \\
\text { (kWh) }\end{array}$ \\
\hline $17 / 10$ & 29,56 & 7,14 & 26,23 & 11,14 & 48,56 & 1,44 \\
\hline $18 / 10$ & 29,93 & 7,04 & 28,16 & 11,10 & 44,07 & 2,09 \\
\hline $19 / 10$ & 30,05 & 7,04 & 29,48 & 11,04 & 39,25 & 2,06 \\
\hline $19 / 10$ & 29,96 & 7,01 & 30,47 & 11,01 & 36,64 & 2,18 \\
\hline $20 / 10$ & 29,43 & 6,98 & 30,58 & 11,01 & 34,81 & 2,24 \\
\hline $21 / 10$ & 29,00 & 6,94 & 30,85 & 10,98 & 35,96 & 2,25 \\
\hline $22 / 10$ & 28,76 & 6,94 & 30,73 & 11,01 & 42,77 & 2,23 \\
\hline $23 / 10$ & 28,67 & 6,94 & 29,29 & 11,10 & 42,16 & 1,72 \\
\hline $24 / 10$ & 28,70 & 6,94 & 26,50 & 11,23 & 48,76 & 1,94 \\
\hline $25 / 10$ & 28,97 & 7,10 & 26,42 & 8,67 & 45,57 & 2,19 \\
\hline $26 / 10$ & 29,45 & 6,08 & 25,11 & 11,33 & 42,49 & 2,24 \\
\hline $27 / 10$ & 30,00 & 6,08 & 27,42 & 11,14 & 35,37 & 2,25 \\
\hline $28 / 10$ & 30,48 & 7,26 & 29,64 & 11,04 & 38,33 & 2,25 \\
\hline $29 / 10$ & 31,11 & 7,20 & 30,71 & 10,98 & 35,39 & 2,25 \\
\hline $30 / 10$ & 31,39 & 7,04 & 31,55 & 10,91 & 34,73 & 2,27 \\
\hline $31 / 10$ & 31,10 & 6,91 & 32,17 & 10,94 & 39,90 & 2,18 \\
\hline $01 / 11$ & 30,83 & 6,88 & 32,36 & 10,91 & 49,35 & 1,40 \\
\hline $02 / 11$ & 30,62 & 6,88 & 32,18 & 10,94 & 47,67 & 2,17 \\
\hline $03 / 11$ & 30,29 & 6,88 & 30,82 & 11,04 & 47,66 & 2,25 \\
\hline $04 / 11$ & 30,26 & 6,88 & 28,76 & 11,10 & 38,20 & 2,24 \\
\hline $05 / 11$ & 30,38 & 6,91 & 26,86 & 8,83 & 34,36 & 2,27 \\
\hline $06 / 11$ & 30,65 & 7,04 & 25,75 & 6,72 & 34,07 & 2,23 \\
\hline $07 / 11$ & 31,03 & 7,14 & 28,08 & 11,10 & 34,92 & 2,27 \\
\hline $08 / 11$ & 29,56 & 5,73 & 26,23 & 11,14 & 48,56 & 1,44 \\
\hline & & & & & & \\
\hline
\end{tabular}

\section{Conforto térmico}

Através da Figura 5, nota-se haver diferença no comportamento da temperatura média e umidade média relativa do ar entre os galpões, ocorridas no lote 1.

De acordo com Abreu \& Abreu (2001) os valores ideais de temperatura média do ar e de umidade relativa do ar são, respectivamente, $20{ }^{\circ} \mathrm{C}$ e de 60 a $70 \%$. Os dois galpões apresentaram valores acima dos citados pelos autores, para temperatura, porém apresentaram valores semelhantes aos encontrados por Perdomo (2004), na avaliação de conforto térmico para aviários, que foi de $30,1^{\circ} \mathrm{C}$. Moura (2001), relata que, com o sistema de nebulização, os frangos toleram temperaturas ambientais acima de $27^{\circ} \mathrm{C}$. O galpão G2 apresentou valores menores de temperatura média do ar em relação ao galpão G1 durante, praticamente, o decorrer do lote, explicado pela eficiência do sistema de climatização do referido galpão, notase, também, que a umidade média relativa do ar ficou abaixo do recomendado por Abreu \& Abreu (2001) e se encontrou pouca diferença de comportamento da umidade média relativa do ar entre os mesmos galpões, esta ocorrência se deve aos baixos valores horários de umidade relativa do ar no período crítico, que se estende entre 11:00 e 15:00 h.

A Tabela 7 ilustra a variação da velocidade de vento nos galpões G1 e G2 nos lotes 4 e 5. Devido ao fato do anemômetro somente ter sido disponibilizado a partir do lote 4, foram analisados apenas esses dois lotes para a variável velocidade de vento.

Vê-se, na Tabela 7, diminuição na velocidade média do vento no box central de cada galpão. Em G1 isto pode ser 


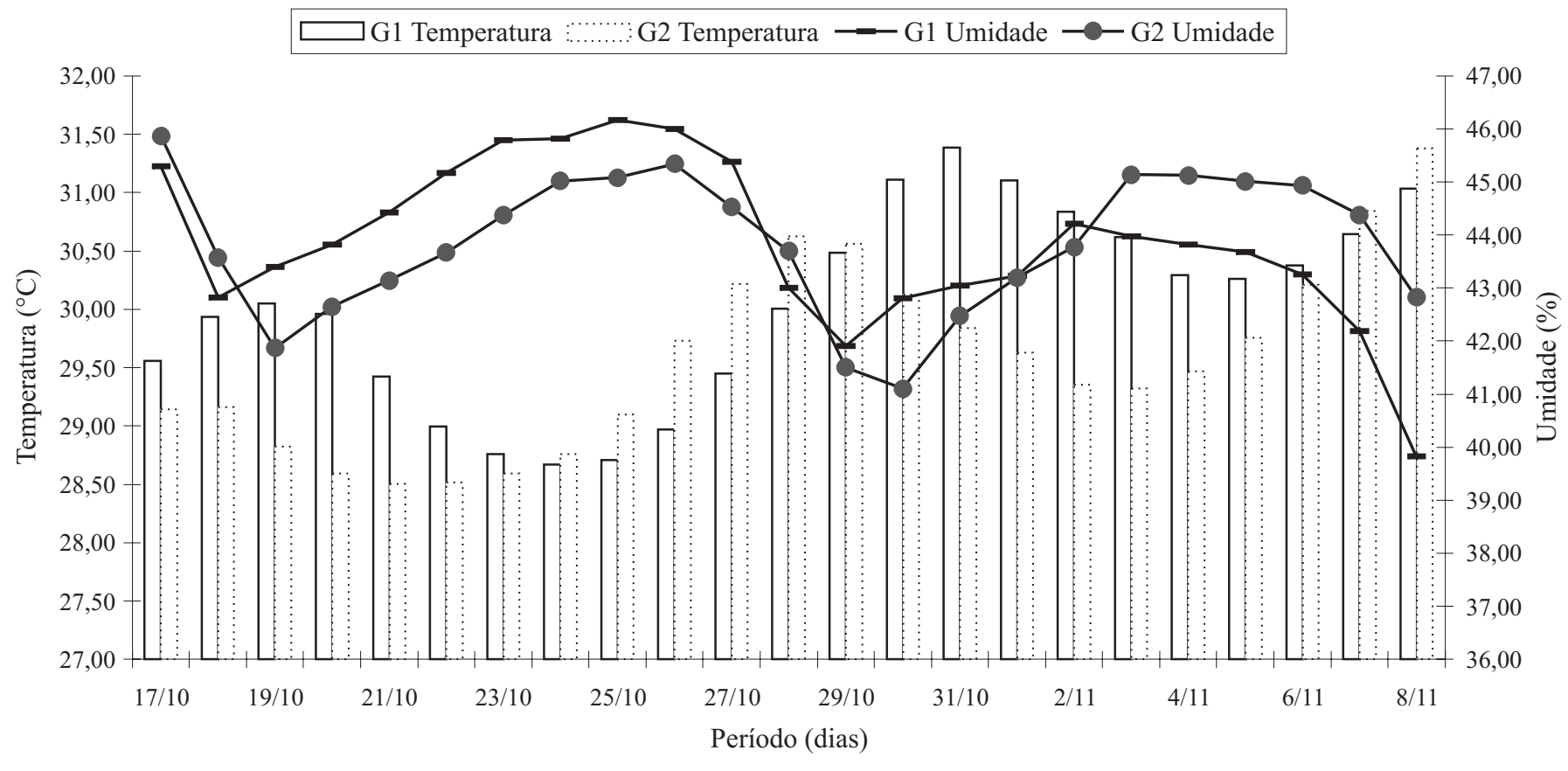

Figura 5. Variação diária do comportamento da temperatura média do ar e umidade relativa do ar entre os galpões no período de 17/10 a 8/11/2002

explicado pelo menor número de ventiladores instalados neste box; já no galpão G2 ocorre a formação de um espaço vazio no box central, provocando a diminuição da velocidade do vento neste local.

Tabela 7. Variação da velocidade de vento no interior dos galpões 1 e 2

\begin{tabular}{cccc}
\hline & \multicolumn{3}{c}{ Velocidade de Vento $\left(\mathbf{m ~ s}^{-1}\right)$} \\
\cline { 2 - 4 } Lote 4 - G1 & Box leste & Box central & Box oeste \\
Lote 4 - G2 & 1,77 & 1,05 & 1,81 \\
Lote 5 - G1 & 1,40 & 1,03 & 1,35 \\
Lote 5 - G2 & 1,60 & 1,10 & 1,70 \\
\hline
\end{tabular}

Os dois sistemas apresentaram valores médios de velocidade de ar dentro dos padrões considerados ideais para aves, que é no mínimo de 0,7 $\mathrm{m} \mathrm{s}^{-1}$ (Rossi, 1998). Em um trabalho realizado por Turco (1998) foram encontrados valores de velocidade de ar superiores ao deste trabalho, o que pode ser explicado pela metodologia e as potências dos equipamentos usados no trabalho serem diferentes das utilizadas pelo autor já citado, não havendo, desta forma, como compará-lo.

\section{Produtividade animal}

São apresentadas, na Tabela 8, as principais variáveis produtivas em ambos os galpões, nos cinco lotes analisados.

Constata-se que a conversão alimentar em ambos os galpões ficou acima do valor padrão da linhagem Ross, citada pela Agroceres Ross (2000) nos lotes 1, 2 e 3, em que as temperaturas foram mais altas. Apenas no lote 4 se obteve temperaturas mais amenas ficando próxima do valor padrão.

Registra-se, também, que, em alguns lotes, para meses quentes, no galpão G1, a conversão alimentar ficou abaixo do valor citado por Patrício (2003), que é de 1,896, e já no galpão G2 se pode notar que os valores ficaram acima dos mencionados por Patrício (2003); deste modo, o galpão G1 apresentou melhor resultado para este índice quando comparado com o autor citado.

Para ambos os galpões, o ganho de peso diário ficou abaixo do padronizado para linhagem usada, conforme Agroceres Ross (2000) que é 57,90 $\mathrm{g} \mathrm{d}^{-1}$, porém o ganho de peso ficou acima do daquele obtido por Patrício (2003) que, na média, foi de $51,00 \mathrm{~g} \mathrm{~d}^{-1}$.

Para o índice mortalidade os valores encontrados tanto no galpão 1 como no galpão 2, que na média ficou em 2,73,

Tabela 8. Variáveis produtivas nos galpões G1 e G2

\begin{tabular}{|c|c|c|c|c|c|c|c|c|c|c|}
\hline \multirow{2}{*}{ Variáveis } & \multicolumn{2}{|c|}{ Lote 1} & \multicolumn{2}{|c|}{ Lote 2} & \multicolumn{2}{|c|}{ Lote 3} & \multicolumn{2}{|c|}{ Lote 4} & \multicolumn{2}{|c|}{ Lote 5} \\
\hline & G1 & G2 & G1 & G2 & G1 & G2 & G1 & G2 & G1 & G2 \\
\hline Pintainhos de 1 dia & 17800 & 24400 & 17978 & 24822 & 18601 & 25174 & 17430 & 24070 & 17472 & 24128 \\
\hline Mortes & 461 & 667 & 401 & 673 & 870 & 616 & 429 & 577 & 521 & 526 \\
\hline Conversão Alimentar (CA) & 1,918 & 1,918 & 1,851 & 1,946 & 2,055 & 1,928 & 1,677 & 1,762 & 1,911 & 1,761 \\
\hline Mortalidade (\%) & 2,58 & 2,73 & 2,23 & 2,71 & 4,67 & 2,44 & 2,46 & 2,39 & 2,88 & 2,18 \\
\hline Idade Média (dias) & 45,90 & 47,27 & 46,20 & 49,38 & 52,97 & 48,77 & 35,11 & 42,02 & 40,47 & 41,56 \\
\hline Ganho de Peso Diário (g) & 52,02 & 50,94 & 53,32 & 52,57 & 56,14 & 54,37 & 50,27 & 54,04 & 50,18 & 51,44 \\
\hline
\end{tabular}


ficaram próximos dos encontrados por Agroceres Ross (2000) como padrão. No G2 observa-se um índice de mortalidade menor que o mencionado por Patrício (2003), que é de 3,42\%. Na média, o galpão 2 em relação a G1 apresentou melhores valores, demonstrando sua eficiência, mas não foi feita, para este tratamento, análise estatística.

De forma geral, observa-se que ambos os galpões apresentam os piores valores em relação aos citados como padrão por Agroceres Ross (2000).

Vê-se, também, que em G2 o desempenho das aves foi melhor, provavelmente em função de melhores condições de conforto térmico, proporcionado pelos exaustores e nebulizadores demonstrando, desta forma, a eficácia de tal sistema.

\section{Análise estatística}

Através da metodologia estatística citada anteriormente, fez-se uma análise estatística simplificada das variáveis: consumo de energia elétrica, temperatura média do ar e umidade relativa do ar, com nível de significância a 5\%.

As Figuras 6, 7 e 8 apresentam as médias obtidas para os dois galpões em relação ao consumo de eletricidade, à temperatura do ar e à umidade relativa do ar, respectivamente.

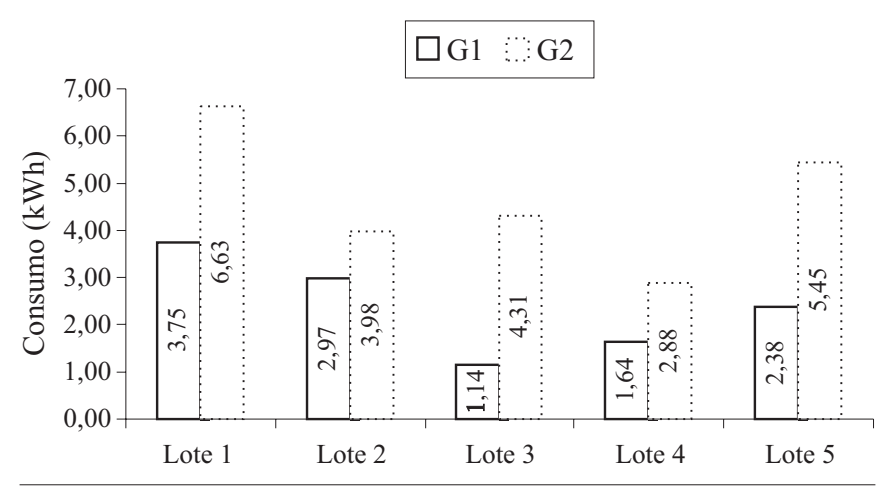

Figura 6. Comparação de médias entre os galpões G1 e G2 para consumo (kWh)

Através da Figura 6 nota-se diferença significativa a nível de 5\%, independentemente do lote analisado e da estação climática em que foi desenvolvido. G2 apresenta, estatisticamente, maiores valores de consumo de energia elétrica que G1, o que era esperado, em virtude do sistema de climatização deste galpão e das potências instaladas dos equipamentos serem maiores que aquelas do G1.

Pode-se observar na Figura 7, que não existem diferenças significativas a nível de 5\% entre os galpões G1 e G2, em relação à temperatura do ar em todos os lotes analisados, não importando a estação do ano em que ocorreu o experimento, este evento demonstra a eficiência do G2 quanto ao seu sistema de climatização, pois mesmo com uma densidade de aves maior, manteve os mesmos índices de TMA de G1, que possui menor quantidade de aves.

Na Figura 8 observa-se que, quando o sistema de nebulização funcionava adequadamente, não havia diferenças significativas (lotes 1 e 2) entre os galpões, para umidade relativa do ar, porém a partir do lote 3 a bomba de nebulização

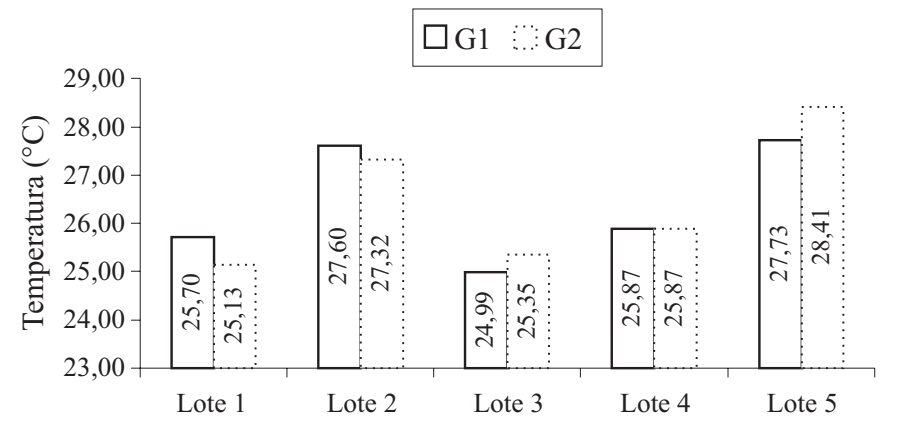

Figura 7. Comparação de médias entre os galpões G1 e G2 para temperatura do ar $\left({ }^{\circ} \mathrm{C}\right)$

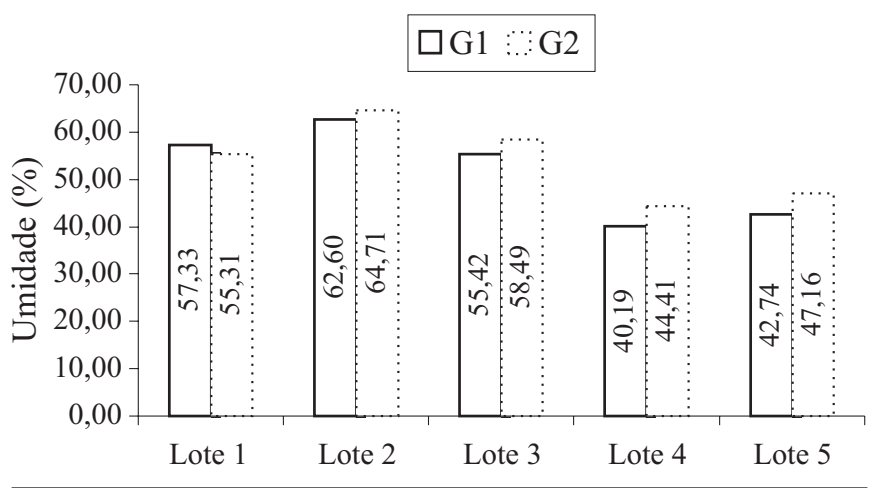

Figura 8. Comparação de médias entre os galpões G1 e G2 para umidade relativa do ar $(\%)$

começou a apresentar falhas no acionamento automático. Constatava-se haver diferenças para as médias desta variável nos três últimos lotes analisados (lotes 3, 4 e 5). Demonstrando, mais uma vez a eficiência do sistema de climatização do galpão G2, mantendo os mesmos índices que os do galpão G1.

\section{CONCLUSÕES}

1. Os índices de eficiência energética foram baixos em ambos os galpões.

2. É necessária a implementação, nesses sistemas avícolas, de técnicas de utilização racional e de conservação de energia elétrica.

3. No consumo de energia elétrica, em ambos os galpões, há diferença significativa comprovada pela realização do Teste $\mathrm{T}$, ou seja, no galpão com alta densidade de animais (G2), existe maior consumo de energia elétrica que no galpão com baixa densidade de animais (G1), entretanto, a quantidade de aves produzidas pelo galpão G2 é 38\% maior que no galpão G1, no mesmo espaço de tempo.

4. Em relação ao conforto térmico, em todos os lotes analisados, o galpão G2 proporcionou os mesmos índices de temperatura do ar e umidade relativa do ar que os do galpão G1.

5. Na análise das principais variáveis produtivas de cada galpão, o galpão G2 apresentou, na média, melhores resultados quando comparados com os do galpão G1. 


\section{AGRADECIMENTOS}

FAPESP, CNPq e CAPES pelo apoio financeiro.

\section{LITERATURA CITADA}

Abreu, V. M. N.; Abreu, P. G. Diagnóstico bioclimático: qual sua importância na produção deaves. Avicultura Industrial, n.1093, p.16-20, 2001. http://www.aviculturaindustrial.com.br. 11 Ago. 2005.

Agroceres Ross. Manual de manejo de frangos. 1.ed. Campinas: Agroceres Editora, 2000. 104 p.

APA-Associação Paulista de Avicultura. http://www.apa.com.br/ framestat.htm. 20 Abr. 2005.

Barnwell, R.; Rossi, A. Maximização da performance em períodos quentes.Avicultura Industrial, v.11, p.72-80, 2003. <http:/ /www.aviculturaindustrial.com.br>. 11 Ago. 2005.

Campos, E. J. Programa de alimentação e nutrição para aves de acordo com o clima-Reprodutoras. In: Simpósio Internacional sobre Ambiência e Instalação na Agricultura Industrial, 1995, Campinas. Anais...Campinas: Facta, 1995, p. 251-257.

Macari, M. O frango adensado. Globo Rural, São Paulo,v.13, n.150, p.48-54, 1998.
Moura, D. J. Ambiência na produção de aves de corte. In: Silva, I. J. O. (ed.). Ambiência na produção de aves em clima tropical. 1.ed., Piracicaba: NUPEA-ESALQ/USP, 2001. p.75-148,

Müller, P. B. Bioclimatologia aplicada aos animais domésticos. 1.ed. Porto Alegre: Sulina Editora, 1982, 158p.

Nããs, I. de A. Princípios de conforto térmico na produção animal. 1.ed. São Paulo: Ícone Editora Ltda, 1989. 183p.

Nããs, I. A.; Miragliotta, M. Y.; Aradas, M. E. C.; Silva, I. J. O.; Baracho, M. S. Controle e sistematização em ambientes de produção. In: Silva, I. J. O. (ed.). Ambiência na produção de aves em clima tropical. 1.ed. Piracicaba: NUPEA-ESALQ/USP, v.1, 2001. 165p.

Rossi, P. R. Sistemas de climatização de instalações avícolas. In: Simpósio Internacional sobre Ambiência e Sistemas de Produção Avícola, 1998, Concórdia. Resumos... Concórdia: Embrapa CNPA. 1998, p.1-6.

Patrício, I. S. Ambiência: a influência do clima na produção de frangos de corte. Avicultura Industrial, n.01,ano 01,ed.1108, p.28-31, 2003. http://www.aviculturaindustrial.com.br. 11 Ago 2005

Perdomo, C. C. Um novo padrão de aviário. . Disponível em <http://www. F:\REVISTA \Revista_Paraíbaltemperatura.mht. 25 Out. 2004.

Turco, J. E. P.; Milani, A. P.; Furlan, R. L.; Macari, M. Análise do consumo de energia elétrica e eficiência de conjuntos motor-ventilador utilizados na avicultura brasileira, Engenharia Agrícola, Jaboticabal, v.18, n.1, p.1-12, Set., 1998. 